\title{
Conflito, identidade e dois sistemas de classificações: a instalação do ITA/CTA em São José dos Campos
}

\author{
Maria Helena Alves da Silva ${ }^{1}$, Maria Aparecida Chaves Ribeiro Papali ${ }^{2}$ e \\ Antonio Carlos Machado Guimarães ${ }^{3}$
}

1 Mestranda em Planejamento Urbano e Regional pela UNIVAP, Graduada em História. É gestora de documentos no CEHVAP - Centro de História e Memória da Univap, Brasil. E-mail: maria.42246@yahoo.com.br

2 Doutorado em História Social pela Pontifícia Universidade Católica de São Paulo, Mestrado em História do Brasil pela Pontifícia Universidade Católica de São Paulo e graduação em História pela Universidade do Vale do Paraíba. Atualmente é professor doutor da Universidade do Vale do Paraíba, atuando na Graduação (Curso de História e Geografia) e na PósGraduação, como docente permanente do Mestrado em Planejamento Urbano e Regional, Brasil. E-mail: papali@univap.br

3 Doutor em Ciências Sociais pela Pontifícia Universidade Católica de São Paulo e Mestre em Antropologia Social e Bacharel em Ciências Sociais pela Universidade Estadual de Campinas. Atualmente é colaborador do Programa de Pós-graduação em Planejamento Urbano e Regional da Universidade do Vale do Paraíba, Brasil. E-mail: ac.guimaraens@gmail.com

Resumo: Este trabalho tem como objetivo explorar as consequências da instalação do Instituto Técnico Aeronáutico - ITA e o CTA - Centro Técnico Aeronáutico na cidade de São José dos Campos no final da década de 1940. Por meio de depoimentos de homens e mulheres que viviam na cidade neste período e publicações de jornais, foi possível concluir que a instalação do ITA-CTA na cidade teve como consequência um conflito entre os moradores e os recém-chegados, em sua maioria estrangeiros, que impactaram a cidade causando um conflito de identidade e resultando em dois sistemas de classificação, percebido principalmente nos mercados, em que eram oferecidos preços diferentes para os moradores e os recém-chegados.

Palavras-chave: São José dos Campos, Industrialização, Conflitos de identidade

Conflict, identity and two classification systems: the installation of ITA / CTA in São José dos Campos

\begin{abstract}
This work aims to explore the consequences of the installation of the Aeronautical Technical Institute (ITA) and the Aeronautical Technical Center (CTA) in the city of São José dos Campos in the late 1940s. Through testimonies of men and women living in City in this period and newspaper publications, it was possible to conclude that the installation of the ITA-CTA in the city had as a consequence a conflict between the residents and the new arrivals, mostly foreigners, that impacted the city causing a conflict of identity and resulting In two classification systems, mainly perceived in markets, where different prices were offered for residents and newcomers.
\end{abstract}

Key words: São José dos Campos, Industrialization, Conflicts of identity

Diversos artigos têm abordado a instalação do ITA e do CTA em São José dos Campos, contando como a instalação do Centro e dessa instituição de ensino superior teve como consequência a criação de diversos empreendimentos de indústria e serviço (SANTOS et al, 2010; Souza e Costa, 2009), e sua relação com o ensino superior no período (BITTENCOURT, 2011).

Escolhido em 1941 pelo Ministério da Aeronáutica para a instalação do CTA e ITA, 
São José dos Campos passou de uma cidade conhecida pelos seus sanatórios e doentes tuberculosos para uma cidade industrial, como consequência da dispersão da concentração industrial da Grande São Paulo, principalmente pelos eixos das recéminauguradas rodovias Presidente Dutra, Anhanguera e Anchieta. Embora existam análises da consequência da instalação do CTA-ITA com novas indústrias e serviços para a cidade, principalmente voltados para o setor aeronáutico; nenhuma publicação até o momento abordou qual seu impacto para os moradores na época.

Figura 1. Localização do Município de SJC (destaque para a Rodovia Pres. Dutra). Distâncias (percurso rodoviário) aproximadas do Município: Rio de Janeiro: $350 \mathrm{Km}$ e São Paulo: $90 \mathrm{Km}$. Fonte: Elaboração dos autores a partir de arquivos do IBGE e DNIT.

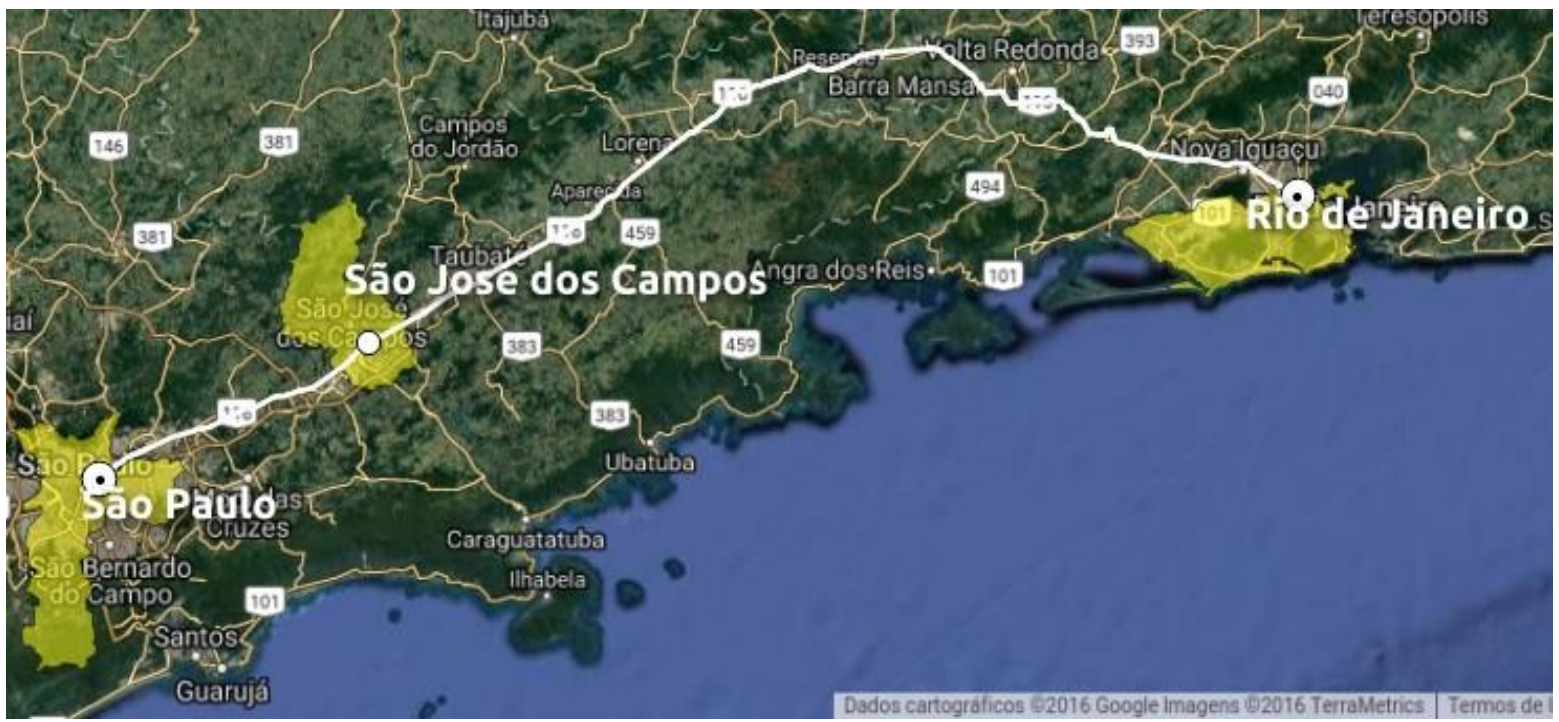

O descompasso das relações entre os recém-chegados e os joseenses podem ser facilmente percebidas em alguns depoimentos em relação a esse período. Wilson Ruiz (1925 - 1991), que estudou e trabalhou no ITA/CTA, conta ${ }^{1}$ que quando chegou na cidade em 1951, as turmas que já estavam alojadas na cidade desde o final da década de 1940 já eram "suficiente pra criar um estilo de vida dentro do ITA, dentro do CTA e em confronto com o estilo de vida da cidade" (RUIZ, 1994, p. 5).

Apesar da cidade já oferecer cinema, restaurantes, bares, hotéis e casas de diversões desde a década de 1920 (GALVÃO, 2001, p. 96), São José dos Campos raramente era visitada pelos 'iteanos'. Havia um grande isolamento e estranhamento entre os habitantes das 'duas cidades' - dentro do campus, haviam clubes, supermercados, hotéis, escolas e capela, de forma que os habitantes de lá poderiam permanecer "sem maiores contatos com a 'cidade'" (OLIVEIRA, 2008, p. 132).

Além disso, havia uma dificuldade com transportes da cidade, que não chegavam até a entrada do CTA, e uma dificuldade nas comunicações, visto que nos primeiros

\footnotetext{
${ }^{1}$ As entrevistas com Wilson Ruiz, Ângela Savastano e Ruy Dória Filho foram realizadas na década de 1990 pelo projeto 'Patrimônio Humano', da Fundação Cultural Cassiano Ricardo, gravados em VHS. Atualmente todos os depoimentos estão transcritos e disponíveis em formato digital no Pró-Memória de São José dos Campos.
} 
anos a língua comum no CTA era o inglês (OLIVEIRA, 2008, p. 132). Álvaro Ferreira Gomes, que chegou na cidade na década de 1960, conta ${ }^{2}$ que ainda havia dificuldades no transporte:

Quando eu cheguei em São José, 61, ainda era burgo. A Nelson D'Ávila e a Paraibuna não eram asfaltadas, você saía do CTA pra ir pro mercado, comprar no mercado central, que é um daqueles ônibus que tem o motor comprido, abre o motor na frente né. Então não tinha aquele portão bonito do CTA né, se ia até o centro pra comprar tinha dois preços; [...] um pro pessoal do CTA, mais caro, evidente, e outro pro pessoal das cidades né (risos). E pra voltar você voltava de carroça. É, era assim São José. Em 1961 né. Quantos habitantes? 62 mil. Né? (GOMES, 2011, p. 10)

Embora esteja se referindo a cidade quase 15 anos depois da instalação do ITA/CTA, a situação de transporte dos moradores era o mesmo desde a sua instalação em fins da década de 1940. A única grande mudança que teve foi a rápida urbanização na cidade nesse período: na década de 1950, segundo dados do IBGE, a população joseense era de 44.804 , dos quais $59,4 \%$ habitavam o perímetro urbano. Dez anos depois, o recensamento mostrou que a cidade contava com 77.533 moradores, dos quais $73,4 \%$ residiam na área urbana. Esse crescimento populacional foi motivado pela industrialização acelerada no município nesse período.

Embora São José dos Campos não possa ser considerado um local isolado e com vida econômica estagnada antes da instalação do ITA e do CTA, pois a cidade já havia recebido, na chamada Fase Sanatorial (1930 - 1950), doentes tuberculosos de diversas regiões do Brasil para serem curados em seus sanatórios, é apenas nesse período que podemos notar novas formas de circulação e consumo, assim como tentativas de metropolização da cidade.

Em seu depoimento, nota-se que o depoente, Gomes achou engraçado a diferença de preços entre bens de consumo entre os joseenses e os moradores do CTA. O mesmo foi percebido por Ângela Savastano, que conta da mudança do sistema de compras na cidade:

Eu me lembro muito bem quando começou mudar esse sistema de compras aqui em São José, foi quando começou a funcionar ... o C, o COCTA, que antes de ser CTA ele foi COCTA, né, Centro de Organização ... do Centro Técnico Aeronáutico. Chamava-se COCTA. Então é veio um pessoal diferente pra São José e esse, e nessa, a primeira diferença que eu como criança senti foi a chegada desse pessoal, porque eles chegaram em São José com os costumes, com o comportamento diferente. Por exemplo no mercado, eles não se portavam como os daqui da região, que a gente negociava, o vendedor a gente é ... é pechinchava né [...] Eles não. Eles não perguntavam nem o preço, às vezes eles compravam muito e compravam e não pegavam nem

\footnotetext{
${ }^{2}$ O depoimento de Álvaro Ferreira Gomes foi recolhido pelo Pró-Memória São José dos Campos em 2011. A transcrição e o áudio digital estão disponíveis em seu Acervo.
} 
o troco. Então foi assim uma... uma... como é que se diz, um modo diferente de negociar. (SAVASTANO, 1992, p. 8)

Pelo seu depoimento, nota-se que pelo comportamento no mercado, havia uma diferenciação entre os dois grupos: os moradores da cidade pechinchavam o preço, enquanto os moradores do CTA, com um comportamento diferente, não perguntavam sequer o preço e não pegavam o troco - bem diferente do comportamento provinciano da cidade.

Como observou Claudio Barreto Viana, a rotina dos professores e alunos envolvia o deslocamento por caminhonetes ou bicicletas, e as idas à cidade eram feitas nos finais de semana, com visitas ao Tênis Clube e bailes nos sábados, visitas em bares, cantinas, restaurantes "e outros lugares menos recomendáveis", além de "algumas brigas com os joseenses, enciumados com a invasão dos 'cadetes da COCTA'", como eram chamados algumas vezes (2012, p.44).

Em depoimento, José Luciano Ferreira Costa contou em maiores detalhes como era essa rotina, e a ida para a cidade:

Nos sábados à noite e domingos íamos á cidade de São José e para isso tínhamos que caminhar até a encruzilhada onde hoje fica o viaduto. Tomávamos um ônibus poeirento e superlotado. O coletivo voltava no fim da sessão do Clnema Paratodos e depois dessa hora, cerca de 9 da noite, soltavam as onças e a cidade ficava deserta. O programa era ficar desfilando na Rua 15 de Novembro, tentando flertar com as meninas, gerando uma má vontade com os rapazes da cidade, o que depois deu em algumas brigas. (SOARES, 2012, p.48-49 ${ }^{3}$ ).

Outros depoentes também contaram como os comportamentos diferenciados resultaram em um choque entre os jovens da cidade. Em depoimento, Ruiz contou mais sobre essa relação conflituosa que surgiu entre os rapazes da cidade e os do ITA em e as moças da cidade, que viam os recém-chegados com mais interesse:

O que aconteceu foi o seguinte: aparentemente os rapazes da cidade é eles não ligavam muito pras moças da cidade, ou não davam muito valor, e o pessoal que veio pra cá, veio gente de todo de todo o lado do Brasil não é, do Sul, de São Paulo, do Rio de Janeiro, Norte, Nordeste, e esse pessoal um pouco abandonado né um pouco sozinho procurava muita cidades e procurava muito contato com as moças da cidade. É e daí nasceu um ciúme tremendo né os rapazes da cidade e os rapazes do CTA. E aí a o que havia era escaramuças, havia uns pegas de vez em quando e isso aí era uma coisa que aparentemente difícil de resolver porque é uma questão de ciúmes né, é uma questão dos rapazes do ITA irem procurar as moças da cidade, e as

\footnotetext{
${ }^{3}$ Os depoimentos referenciados com 'SOARES' constam no livro'Histórias para contar, Amigos para Encontrar', publicado em 2012, organizados por Ana Paula Soares. Cita-se no texto o nome do depoente, mas a referência será feita a organizadora do livro.
} 
moças da cidade, naturalmente muito lisonjeados, porque haviam muitos rapazes atraentes né, e eles eram uma coisa nova pra moças da moças da cidade, eram rapazes que falavam bem, com sotaques diferentes né, com roupagem diferente, com atitudes diferentes, e daí o choque dos rapazes e havia de vez em quando havia briga mesmo (...) (RUIZ, 1994, p. 5)

A relação entre as moças joseenses e os estudantes do ITA chegaram a ser alvo de comentários do jornal local, o Correio Joseense, quando em outubro de 1955 publicou-se uma notícia em que os alunos, "conhecendo algumas moças levianas, estendem o adjetivo a todas as jovens de São José dos Campos". Os alunos se defenderam: o presidente do Centro Acadêmico Santos Dumont, órgão oficial de representantes do corpo discente do ITA, publicou:

Não temos conhecimento de haver qualquer aluno dêste instituto feito essa acusação: e se algum deles tivesse feito tal generalização injusta, improcedente e absurda, não deveriam todos os seus colegas ser responsabilizados por semelhante ato de incorreção de má educação e de ingratidão para com a culta e digna sociedade joseense, que tão hospitaleiramente nos tem acolhido e que tantas vezes nos tem honrado com demonstrações de confiança e amizade. (CORREIO, 1955, fazer cit).

Dentre esses dois pontos abordados no artigo - o relacionamento entre os jovens e a diferenciação do mercado, talvez o evento que tenha o maior significado para esta diferenciação e descompasso entre a vida e os conhecimentos dos 'iteanos' e os moradores tenha sido evidenciado pelo depoente Ruy Rodrigues Dória Filho, em que ele conta como que os estudantes do ITA fizeram uma 'brincadeira' com os moradores de São José dos Campos ao fingir que tinham construído um foguete:

eu me lembro de um fato até pitoresco e muito engraçado, pelo inusitado do fato em si na época, os alunos do ITA construíram, acho que deve ter sido por volta de 1960, 1961, na época do Sputinik, deve ser por aí, construíram um foguete, montaram o foguete atrás da Igreja da matriz ali na orla do Banhado e convocaram a população toda para ir ver o lançamento desse foguete, e era tudo uma montagem, uma brincadeira dos alunos do ITA, e a população inteira de São José foi assistir o lançamento do foguete construído aqui em São José dos Campos, era um negócio interessante para época né.(FILHO, 1992, p. 5) 
Figura 2. A turma de 1958 posa com o foguete falso, chamado de 'RX-1'. Arquivo da AEITA (SOARES, 2012, p.123)

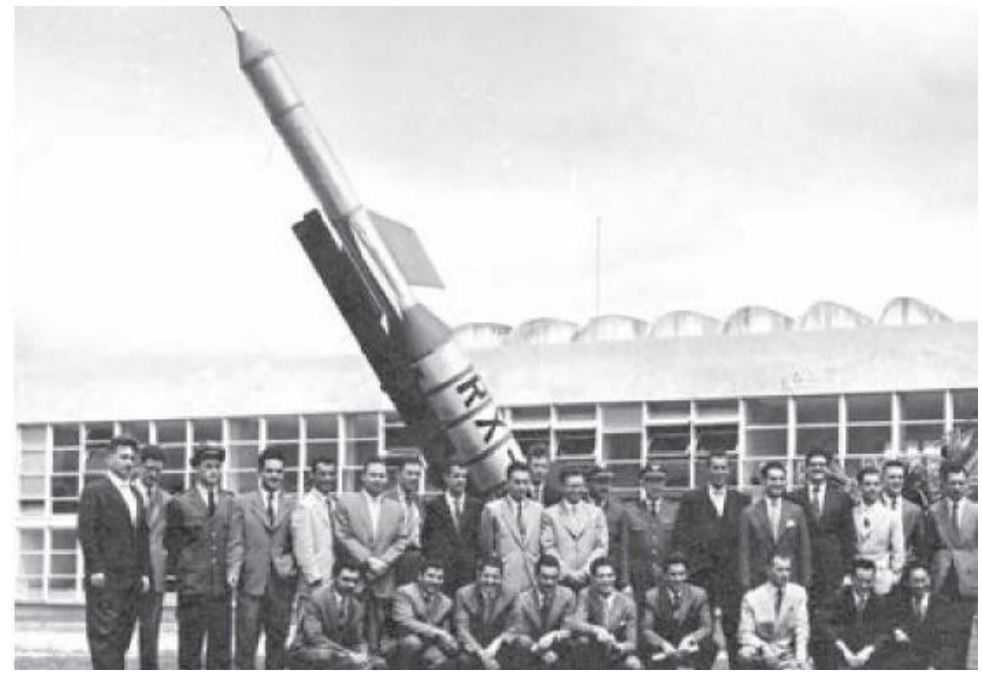

Conhecida como "O trote do foguete", essa história chegou a virar capítulo no livro '"Histórias par Contar, Amigos para Encontrar", publicado pelo AEITA - Associação dos Engenheiros do ITA, em 2012. O autor desse capítulo, Décio Fischetti, conta que o evento aconteceu em 1958: a União Soviética havia acabado de lançar ao espaço o satélite Sputnik, e havia muita admiração e curiosidade. Os alunos, como parte das comemorações dos '100 dias' antes da formatura, geralmente faziam alguma comemoração. Até que na Rua 15 de Novembro, na Loja Diamante, apareceu uma 'réplica' do Sputnik, anunciado como 'o primeiro satélite artificial brasileiro' a ser lançado na cidade de São José dos Campos. Os alunos, assim que viram, perceberam que se tratava de uma brincadeira - mas não sabiam se seria originário de outros alunos ou do lançamento de algum produto. Na Rádio Clube e no Jornal Valeparaibano foram divulgadas informações que, embora fossem voltadas para o público local, se espalhou para o Vale do Paraíba.

Figura 3. Recorte do jornal 'Valeparaibano' anunciando o lançamento do satélite em São José. Fonte: (SOARES, 2012, p. 123).

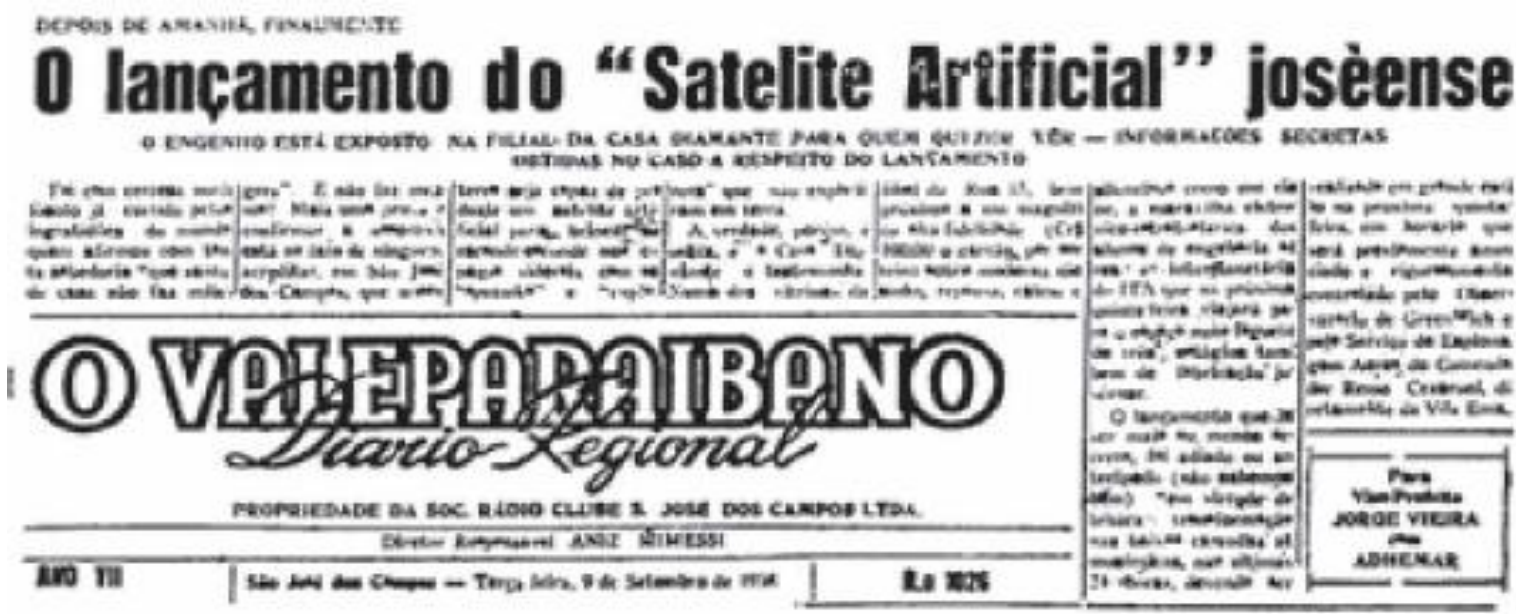


No dia 11 de setembro, conforme conta o depoimento de Filho, foi montada uma rampa atrás da Igreja Matriz, com instrumentos, medidores e os primeiros alunos chegando a o local:

Foi quando eu cheguei com alguns colegas para assistir a 'pegadinha', imaginando que tipo de reação poderia ocorrer com todo aquele povo lá. E eu já via estacionados ônibus e Kombis com gente de Jacareí, Taubaté, Caçapava... A cidade e Região estavam parados para o evento sensacional. Os cinemas cancelaram as sessões noturnas [...] (FISCHETTI, 2012, p. 124)

Depois de tudo arrumado e quase três horas de encenação, os alunos, fantasiados de cientistas, com roupas de amianto, fazem uma contagem regressiva - começa a sair uma fumaça do foguete, que se transforma em fogos de artifício, enquanto os alunos tiraram os aventais para mostrarem que estavam usando fantasias e com a faixa 'Centediário 1958'.

O povo, atônico, começou a perceber a 'pegadinha' (pegadona?!) e alguns até se juntaram para agredir os autores. Felizmente, a presença de militares e uma boa conversa transformaram a brincadeira numa noite inesquecível para a cidade. O que ocasionou, porém, reclamações oficiais e notas nos jornais. (FISCHETTI, 2012, p. 125)

Curiosamente, tal evento não foi reportado pelo jornal local, o 'Correio Joseense', que é uma das maiores referência no que se refere a notícias da cidade. Como é possível observar pelo depoimento de Fischetti, o evento deixou os moradores e visitantes extremamente irritados, a ponto que foi necessário a intervenção dos militares.

\section{CONSIDERAÇÕES FINAIS}

Esse breve estudo teve como objetivo levantar e analisar alguns conflitos que aconteceram entre os moradores de São José dos Campos e os alunos do recéminstalado ITA - Instituto Técnico Aeronáutico. Em outros artigo publicados, nota-se que há, entre os autores, um senso comum que diz que foi o CTA e o ITA os impulsionadores da industrialização da cidade. Como analisa Hugo de Oliveira Piva,

A cidade, caipira e provinciana, era um grande sanatório para tuberculosos. É uma satisfação ver como o CTA impulsionou toda a região, tornando-a esse rico expoente do ensino, pesquisa e indústria de projeção internacional (SOARES, 2012, p.48)

Nota-se que embora se faça constante referência ao estado 'provinciano' da cidade, ao mesmo tempo são referenciados pelos depoentes as diversas distrações oferecidas pela cidade, que eram aproveitadas pelos jovens alunos nos finais de semana. 
Foram nessas ocasiões que surgiram os principais conflitos entre esses dois grupos, ainda pouco estudados: os estudantes entravam em conflito com os jovens moços da cidade em disputa com as moças da região - consideradas 'levianas' por alguns, pelo que se pode notar por uma publicação da época; e a diferença entre comportamento e situação econômica variava a tal ponto que foram criados preços diferenciados para os moradores da cidade e os moradores do CTA. Consideramos que o grande ápice desse descompasso foi a brincadeira que os alunos fizeram com os moradores da região, montando um foguete falso e que precisou da intervenção da polícia para que não terminasse em um embate entre os dois grupos.

Conclui-se, por meio de depoimentos e publicações da época, houve um grande embate entre os dois grupos na cidade, diferenciados por seu local de moradia, nível educacional e econômico. Serão necessários estudos mais aprofundados para determinar até que ponto essas relações conflituosas determinaram o futuro da cidade, uma vez que em meio a conflitos, geralmente a cidade e sua elite ou se submetem aos novos moradores ou tentam se articular para ganhar mais espaço e reconhecimento.

\section{REFERÊNCIAS}

BITTENCOURT, Agueda Bernadette. La cooperación científica internacional y la creación de CAPES. Revista Colombina de Educacíon, Num. 61.

FILHO, Ruy Dória. Entrevista concedida ao projeto de Patrimônio Humano de São José dos Campos em 1992. DVDS e transcrição disponíveis no Pró-Memória de São José dos Campos.

FISCHETTI, Décio. 0 trote do foguete - o dia em que a cidade parou para ver o lançamento do RX-1. In: Histórias para Contar, Amigos para Encontrar. SOARES, Ana Paula (Org.). São José dos Campos, SP: ITA/CTA, 2012.

GALVÃO, Bah. Homens e Mulheres que Fizeram São José dos Campos no século 20. São José dos Campos: Editora Jac, 2001.

GOMES, Álvaro Ferreira. Entrevista cedida ao Pró-Memória de São José dos Campos em 2011. Áudio e transcrição disponíveis no Pró-Memória São José dos Campos.

OLIVEIRA, Nilda Nazaré Pereira. Entre o criar, o copiar e o comprar pronto: a criação do ITA e do CTA como instituições de ensino e pesquisa para a consolidação da indústria aeronática brasileira (1945-1990). 2008. 258 páginas. Tese do Programa de Pós-Graduação em História Social da Faculdade de Filosofia, Letras e Ciências Humanas da Universidade de São Paulo.

RUIZ, Wilson. Entrevista cedida ao Projeto Patrimônio Humano, pela Fundação Cultural Cassiano Ricardo. Vídeo e transcrição disponíveis no Pró-Memória São José dos Campos.

SAVASTANO, Ângela. Entrevista concedida ao projeto de Patrimônio Humano de São José dos Campos em 1992. DVDS e transcrição disponíveis no Pró-Memória de São 
José dos Campos.

SANTOS, Isabel Cristina dos Santos; MORAIS, Paulo Renato de; CABRAL, Arnoldo Souza; OLIVEIRA, Edson Aparecida de Araújo Querido. Empreendedorismo, Inovação tecnológica e desenvolvimento regional. XXX Encontro Nacional de Engenharia de produção. São Carlos, SP, 12 a 15 de outubro de 2010.

SOARES, Ana Paula (Org.). Histórias para Contar, Amigos para Encontrar. São José dos Campos, SP: ITA/CTA, 2012.

SOUZA, Adriane Aparecida Moreira; COSTA, Wanderley Messias da. Atividades industriais no interior de São Paulo, uma análise da formação do complexo tecnológicoindustrial-aeroespacial de São José dos Campos. Revista INTERFACE - Natal/RN - v.6 - n. 2 - jul./dez. 2009.

Artigo recebido em 21 de junho de 2017. Aprovado em 01 de agosto de 2017. 